\title{
Systemic lupus erythematosus complicated with macrophage activation syndrome mimicking COVID-19 multisystemic inflammatory syndrome in children
}

\author{
Jesús Domínguez-Rojas ${ }^{1}$, Noé Atamari-Anahui2*, Kenny Chonlon-Murillo ${ }^{3}$, Mariela Tello ${ }^{4}$, and \\ Álvaro Coronado-Muñoz ${ }^{5}$ \\ ${ }^{1}$ División de Cuidados Críticos Pediátricos, Departamento de Pediatría, Hospital Nacional Edgardo Rebagliati Martins, Lima, Peru; ${ }^{2}$ Unidad de \\ Investigación para la Generación y Síntesis de Evidencias en Salud, Vicerrectorado de Investigación, Universidad San Ignacio de Loyola, Lima, \\ Peru; ${ }^{3}$ Departamento de Pediatría, Hospital Nacional Edgardo Rebagliati Martins, Lima, Peru; ${ }^{4}$ Instituto Nacional de Salud del Niño-San Borja, Lima, \\ Peru; ${ }^{5}$ Department of Pediatrics, McGovern Medical School, University of Texas, Houston, Texas, United States of America
}

\begin{abstract}
Background: Macrophage activation syndrome (MAS) is characterized by excessive activation of macrophages and lymphocytes, leading to multiorgan dysfunction. As the initial manifestation of systemic lupus erythematosus (SLE), MAS is rare in children. Due to the COVID-19 pandemic, it is vital to identify the MAS as it shares similar characteristics with the multisystem inflammatory syndrome in children (MIS-C). Case report: We report the case of an 11-year-old male adolescent with symptoms of MIS-C. Although with negative results of RT-PCR (reverse transcription-polymerase chain reaction) and serology for SARS-CoV-2, contact with a positive COVID-19 relative was reported. When admitted to a referral hospital center, the patient received standard treatment for MIS-C. Although the same scheme was given on three occasions, the patient showed no response to initial therapy. Thus, the patient was classified as a refractory case. When the study was extended to other differential diagnoses, we found MAS associated with SLE. Therefore, the patient was treated with etoposide, cyclosporine, dexamethasone, and methotrexate and showed a good clinical response. Conclusions: MAS associated with SLE is rare in the pediatric population. MAS shares inflammatory markers with the MIS-C and is often confused with rheumatologic, infectious, and neoplastic entities. Reporting this case is important to identify differential diagnoses in patients presenting as MIS-C and decide on timely treatment, as it could be harmful or even fatal if a definitive diagnosis is not obtained on time.
\end{abstract}

Keywords: Macrophage activation syndrome. Systemic lupus erythematosus. Child. SARS-CoV-2.

\section{Lupus eritematoso sistémico complicado con síndrome de activación macrofágica mimetizando el síndrome multisistémico inflamatorio secundario a la COVID-19 en pediatría}

\section{Resumen}

Introducción: El síndrome de activación de macrófagos (SAM) se caracteriza por una activación excesiva de los macrófagos y de los linfocitos que conduce a una disfunción multiorgánica. Como manifestación inicial del lupus eritematoso sistémico (LES), el SAM es poco común en la infancia. Debido a la pandemia de COVID-19, es importante identificar el SAM, ya que

\section{Correspondence:}

*Noé Atamari-Anahui

E-mail: noe.atamari@gmail.com
Date of reception: 07-04-2021

Date of acceptance: 08-06-2021

DOI: 10.24875/BMHIM.21000064
Available online: 16-12-2021

Bol Med Hosp Infant Mex. 2021;78(6):642-646

www.bmhim.com

1665-1146/C 2021 Hospital Infantil de México Federico Gómez. Published by Permanyer. This is an open access article under the CC BY-NC-ND license (http://creativecommons.org/licenses/by-nc-nd/4.0/). 
comparte características similares con el síndrome inflamatorio multisistémico en niños (MIS-C, por sus siglas en inglés). Caso clínico: Presentamos el caso de un varón de 11 años con síntomas de MIS-C. Resultó negativo en la prueba de reacción en cadena de la polimerasa con retrotranscriptasa y en la serología para SARS-CoV-2, aunque reportó contacto con un familiar positivo para COVID-19. Ingresó en un centro hospitalario de referencia y recibió tratamiento estandarizado para MIS-C. A pesar de recibir el mismo esquema en tres ocasiones, no mostró respuesta a la terapia inicial, por lo que fue clasificado como caso refractario. Al ampliar el estudio para otros diferenciales, se encontró SAM asociado con LES, por lo que el paciente recibió tratamiento con etopósido, ciclosporina, dexametasona y metotrexato, y mostró buena respuesta clínica. Conclusiones: La asociación entre el SAM y el LES es rara en la población pediátrica. El SAM comparte marcadores inflamatorios con el MIS-C y suele confundirse con enfermedades reumatológicas, infecciosas y neoplásicas. La importancia de reportar este caso es identificar los diagnósticos diferenciales en los pacientes que se presentan como MIS-C, y decidir el tratamiento con prontitud, pues podría ser dañino o incluso fatal si no se obtiene un diagnóstico definitivo a tiempo.

Palabras clave: Síndrome de activación macrofágica. Lupus eritematoso sistémico. Niño. SARS-CoV-2.

\section{Introduction}

Macrophage activation syndrome (MAS) is characterized by an immune dysregulation secondary to macrophage and lymphocyte proliferation leading to systemic hyperinflammation. MAS associated with systemic lupus erythematosus (SLE) is rare. Fukaya et al. reported 18 patients with hemophagocytic syndrome and SLE among 350 patients admitted with SLE to a hospital in Japan between 1997 to 2007 (a study population-specific frequency of $5 \%)^{2}$.

Multisystemic inflammatory syndrome in children (MIS-C) associated with SARS-CoV-2 is a recently described entity ${ }^{3}$. Rigorous use of clinical criteria for MIS-C without considering it a dynamic, evolving entity with imprecise limits could lead to diagnostic errors. Regardless of a consensus international definition, it is necessary to apply medical reasoning in managing these patients. Given that MIS-C presents with specific signs and symptoms and different clinical presentations ${ }^{4}$, we report this case to describe the association between MAS and SLE in a male pediatric patient initially diagnosed with MIS-C due to overlapping clinical features.

\section{Clinical case}

We describe the case of a previously healthy 11-yearold Hispanic male from Lima, Peru, who was admitted to the pediatric emergency department with a history of skin erythema, general discomfort, headache, and arthralgias with a duration of one week. One day before admission, he presented with nausea, vomiting, abdominal pain, and fever. RT-PCR (reverse transcription-polymerase chain reaction) for SARS-CoV-2 was negative; however, two months earlier, the mother was positive for COVID-19.

Oxygen saturation was $98 \%$, heart rate $110 \mathrm{bpm}$, temperature $37.6^{\circ} \mathrm{C}$, respiratory rate $20 \mathrm{rpm}$, blood pressure 106/70 $\mathrm{mmHg}$, weight $57 \mathrm{~kg}$, and he showed a facial expression consistent with pain. On physical examination, he had an erythematous rash on the anterior region of the right chest and the palms of the hands, hip arthralgia, and chest pain over the ribs on palpation. Bilateral cutaneous findings are shown in Figure 1. The patient presented with diffuse abdomen tender to palpation, McBurney (+), fever, and decreased joint mobility ranges in arms and legs due to pain. Laboratory test results showed inflammatory markers including leukocytosis, lymphopenia, and elevated C-reactive protein levels, $d$-dimer, elevated pro-B natriuretic peptide, ferritin, and fibrinogen.

With the diagnosis of MIS-C, the patient was treated with intravenous immunoglobulin (2 g/ $/ \mathrm{kg} /$ dose), acetylsalicylic acid (50 mg/kg/day), and methylprednisolone acetate $(2 \mathrm{mg} / \mathrm{kg} /$ day). Upon clinical and inflammatory marker improvement, he was discharged. However, on the ninth day since the initial presentation, he was readmitted with a similar clinical picture, fever, and elevated inflammatory markers. Therefore, the admission diagnosis was refractory MIS-C associated with suspected sepsis. Extensive empirical treatment of antibiotic coverage and a second dose of immunoglobulin and corticosteroids was started. An echocardiography study showed normal coronary arteries, a patent foramen ovale $(1.6 \mathrm{~mm})$, mild left ventricular diastolic dysfunction, no signs of pulmonary hypertension, and no pericardial effusion. An abdominal CT scan showed hepatosplenomegaly, and a chest X-ray demonstrated bilateral pulmonary consolidation. Forty-eight hours after initiating treatment, fever persisted, and a diffuse exanthema was observed. Inflammatory markers were elevated, including interleukin-6 (Table 1). The third cycle of immunoglobulin with corticosteroid pulse was administered, and prophylactic anticoagulation was ordered. The list of differential diagnoses was reviewed, 


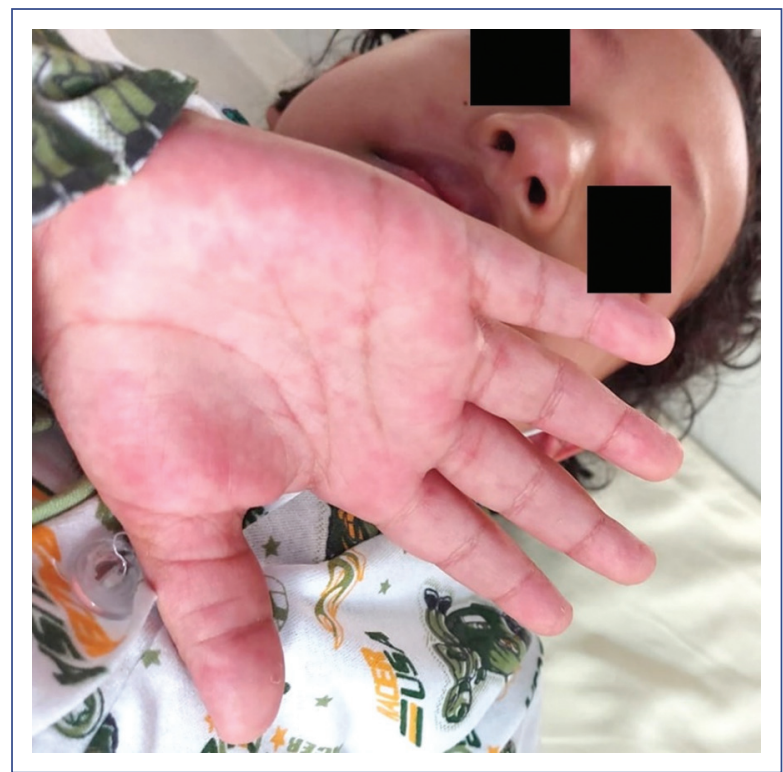

Figure 1. Maculopapular eruptions on hands.

and it was decided to extend the study to infectious, hemato-oncologic, and rheumatologic causes.

On day 22 of admission, the patient remained febrile; laboratory results revealed a quantitative increase of inflammatory markers, worsening anemia, worsening thrombocytopenia, severe hyperferritinemia, severe transaminitis, hypertriglyceridemia, and hypocomplementemia (C3 and C4) (Table 1). We performed a bone marrow aspirate, which showed granulocytes and platelet hemophagocytosis with the presence of histiocytes. A positive antinuclear antibody with a speckled nucleated pattern was obtained in titer 1/320: autoantibodies against positive Ro52 recombinant antigens and positive lupus anticoagulant. The infectious study revealed positive serology for Bartonella henselae. Given the diagnosis of MAS due to SLE, a chemotherapy treatment protocol was initiated, including etoposide, cyclosporine, dexamethasone, and methotrexate. The patient presented complications secondary to chemotherapy (febrile neutropenia, severe pancytopenia) and received broad-spectrum antibiotic coverage, including Bartonella therapy and antifungal treatment. As we observed a good clinical response to treatment and normal paraclinical tests, home discharge and outpatient follow-up was indicated.

\section{Discussion}

The new presenting condition secondary to SARSCoV-2 infection in children is MIS-C ${ }^{3}$. Its early recognition for pediatricians could be challenging, and the appropriate indication of therapeutic options is still under debate. There may be a high bias in MIS-C diagnosis during the pandemic, also considering that diagnostic definitions are broad.

Here, we report a case with a problematic diagnostic pathway due to a presentation similar to MIS-C, hemophagocytic lymphohistiocytosis (HLH), and macrophage activation syndrome (MAS). Several diseases may present with similar clinical manifestations, so we may currently overestimate the diagnosis of MIS-C in the pediatric population. Similarly, the use of empiric therapy without a definitive diagnosis and the cost-benefit should be evaluated. MIS-C is a syndrome and a new pathologic entity with a solid epidemiologic correlation. It is a primary diagnosis in any patient with clinical presentation, as in this case, but it is not always the presenting disease.

The sequelae and mortality of pediatric SLE are associated with several risk factors: age at early diagnosis, male sex, and non-Caucasian race (African American, Asian, and Hispanic). Most children present with fever, arthralgia, arthritis, rash, myalgia, fatigue, and weight loss. These symptoms are quite nonspecific, so the patient must meet the diagnostic criteria determined by the American College of Rheumatology, as described in this case ${ }^{5}$. Gracia-Ramos presented a review of cases linking lupus erythematosus and SARS-CoV-2. However, the presentation of MAS mimicking MIS-C in a pediatric patient has not been described, thus presenting different challenges ${ }^{6}$. A difference of presentation between MIS-C and MAS can be observed in Figure 2.

MAS falls within the "cytokine storm syndrome" spectrum and is characterized by low blood cell count (cytopenia) and multiorgan failure, involving the lung, liver, kidney, and heart ${ }^{1}$. In addition to elevated serum cytokines, elevated ferritin concentrations are characteristic of this syndrome. Macrophages expressing CD163 are the source of ferritin; in this sense, elevated serum ferritin is also a biomarker of poor prognosis ${ }^{1}$.

In the case of negative RT-PCR and serology for SARS-CoV-2 and high clinical suspicion of MIS-C, repeat serology is recommended 3-4 weeks after admission. It has been described that $26-55 \%$ of patients with MIS-C have positive RT-PCR and up to $90 \%$ positive $\lg G$ serology ${ }^{7,8}$. The broad diagnosis that mentions a positive contact as a diagnostic criterion can be misleading.

MAS-associated SLE is rare. Children with rheumatologic conditions such as SLE and Kawasaki disease 
Table 1. Evolution of paraclinical results during hospitalization

\begin{tabular}{|c|c|c|c|c|c|c|c|c|c|c|c|c|}
\hline \multirow[t]{2}{*}{ Laboratory } & \multirow{2}{*}{$\begin{array}{l}\text { Reference } \\
\text { range }\end{array}$} & \multicolumn{11}{|c|}{ Days of hospitalization } \\
\hline & & 0 & 4 & 9 & 11 & 12 & 15 & 22 & 37 & 39 & 48 & 59 \\
\hline Leukocytes $\left(\times 10^{3} / \mu \mathrm{L}\right)$ & $5.0-14.5$ & 20.26 & 11.30 & 25.76 & 21.63 & 16.28 & 11.45 & 9.07 & 2.45 & 5.29 & 11.01 & 8.61 \\
\hline Neutrophils $\left(\times 10^{3} / \mu \mathrm{L}\right)$ & $1.8-8.0$ & 17.91 & 8.60 & 24.12 & 19.65 & 14.11 & 9.02 & 6.4 & 0.78 & 2.70 & 6.09 & 4.04 \\
\hline Lymphocytes (x103/pL) & $0.9-5.2$ & 1.10 & 1.69 & 1.05 & 1.29 & 0.98 & 1.55 & 1.98 & 1.05 & 1.38 & 3.73 & 4.13 \\
\hline Hemoglobin (g/dL) & $11.5-15.5$ & 12.7 & 12 & 11.3 & 11.2 & 10.9 & 11.1 & 10.2 & 12 & 11.1 & 9.9 & 9.9 \\
\hline Platelets $\left(x 10^{3} / \mu \mathrm{L}\right)$ & $150-400$ & 318 & 309 & 382 & 405 & 309 & 229 & 79 & 195 & 132 & 393 & 517 \\
\hline Urea (mg/dL) & $22-55$ & 30 & 32.1 & 21.4 & 27.8 & 21.4 & 15 & 25.7 & - & 19.3 & 21.4 & 44.9 \\
\hline Creatinine $(\mathrm{mg} / \mathrm{dL})$ & $0.3-0.7$ & 0.45 & 0.29 & 0.44 & 0.48 & 0.34 & 0.34 & 0.36 & - & 0.38 & 0.32 & 0.58 \\
\hline Albumin (g/dL) & $3.2-4.8$ & 4.38 & 3.66 & 3.42 & 3.23 & 2.78 & 2.86 & 3.09 & 4.17 & 3.44 & 3.42 & 4.95 \\
\hline LDH (U/L) & $120-246$ & 297 & 304 & - & - & 368 & 723 & 2760 & 671 & 665 & 582 & 291 \\
\hline Cholesterol (mg/dL) & $<200$ & - & - & 109 & - & 76 & 102 & 104 & - & - & 164 & 254 \\
\hline Triglycerides (mg/dL) & $<250$ & - & - & 117 & - & 93 & 102 & 313 & - & - & 316 & 275 \\
\hline Ferritin (ng/mL) & $28-365$ & 1409 & - & 5985 & 8592 & - & 32473 & 75706 & - & - & 5776 & 1949 \\
\hline $\begin{array}{l}\text { C-reactive protein } \\
(\mathrm{mg} / \mathrm{dL})\end{array}$ & $0-1.0$ & 23.7 & 12.7 & 10.8 & 13.4 & 17.3 & 11.4 & 8.4 & - & 10.8 & 3.7 & - \\
\hline GOT (U/L) & $10-35$ & 29 & 43 & 43 & 40 & 62 & 76 & 651 & 153 & 141 & 125 & 64 \\
\hline GPT (U/L) & $10-49$ & 34 & 30 & 48 & 37 & 44 & 37 & 424 & 189 & 191 & 159 & 148 \\
\hline CPK (U/L) & $34-145$ & 23 & - & 18 & - & - & 23 & - & - & - & - & - \\
\hline CPK-MB (ng/mL) & $0-6$ & - & 0.3 & - & $<0.3$ & - & - & - & - & - & - & - \\
\hline Pro-BNP (pg/mL) & $0-125$ & 9.3 & 278.1 & - & - & - & - & 158 & - & - & - & - \\
\hline Troponins (ng/mL) & $0-0.01$ & $<0.003$ & $<0.003$ & - & 0.005 & - & - & $<0.003$ & - & - & - & - \\
\hline Fibrinogen (mg/dL) & $200-400$ & 632.04 & 468.9 & 521.02 & 420.49 & 371.4 & 342.07 & 201.62 & - & 422.69 & 453.45 & 561.2 \\
\hline D-dimer (ug/mL) & $0-0.54$ & 5.23 & - & 1.7 & 4.3 & 22.95 & 16.41 & 29.37 & - & 6.45 & - & - \\
\hline IL-6 (pg/mL) & $0-2.0$ & - & - & - & 77.2 & - & - & - & - & - & - & - \\
\hline
\end{tabular}

BNP, B-natriuretic peptide; CPK, creatine phosphokinase; CPK-MB, creatine phosphokinase myocardial band; GOT, glutamic oxaloacetic transaminase; GPT, glutamic pyruvic transaminase; IL-6, interleukin 6; LDH, lactate dehydrogenase.

are also at risk for MAS ${ }^{1}$. Borgia et al. reported $9 \%$ of patients with SLE and MAS in a cohort of children in Canada $^{9}$. In this study, most patients with MAS were female, and the mean age at diagnosis of SLE was 13 years $^{9}$. MAS is primarily described in patients with juvenile idiopathic arthritis (JIA) but can occur in different rheumatologic diseases. Bennett et al. described 121 patients with MAS; only 19 pediatric patients had MAS secondary to $S_{L E}{ }^{10}$. The case described here falls into this reduced group of patients. In the previously mentioned study, patients with SLE presented similar mortality but required more ICU care, more mechanical ventilation, and higher vasopressor support ${ }^{10}$.

Our patient was diagnosed with MAS secondary to SLE. Delayed treatment of this condition could have been life-threatening and could have progressed into multiorgan failure. Treatment of secondary MAS is directed at the underlying condition ${ }^{1}$. Gupta et al. reported a case of a 15-year-old female patient with MAS secondary to SLE who received methylprednisolone pulses and oral cyclosporine with a good response to treatment ${ }^{11}$. This report was similar to another case in a 22-year-old male treated with methylprednisolone pulses and azathioprine ${ }^{12}$. Similar to previous reports, 


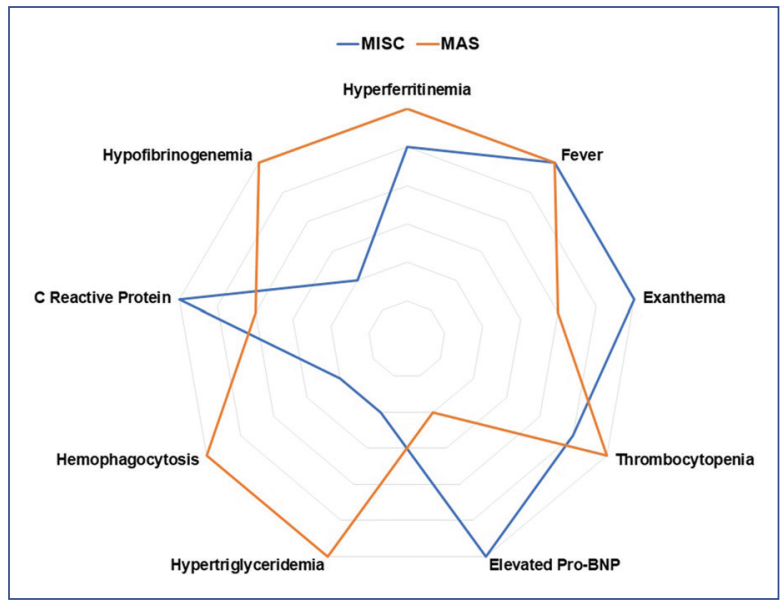

Figure 2. Differential diagnosis of multisystem inflammatory syndrome in children (MIS-C) and macrophage activation syndrome (MAS).

BNP, B-natriuretic peptide.

our patient had an adequate evolution with the proposed treatment for this disease ${ }^{13}$. In addition, the patient was managed by a multidisciplinary group including oncology and rheumatology, with a hybrid therapy scheme for HLH and MAS.

The coexistence of SLE and MAS has overlapping clinical features, so a high level of suspicion is necessary for diagnosis. Rapid initiation of treatment of MAS is of extreme importance, as it is a potentially fatal and rapidly progressive condition, even with adequate treatment.

In conclusion, MAS-associated SLE is rare. Identification of differential etiologic diagnoses that share MIS-C criteria is critical to avoid delays in therapies. MIS-C refractory to treatment should raise suspicion of other etiologies such as MAS, which can be fatal if a definitive diagnosis is not reached.

\section{Ethical disclosures}

Protection of human and animal subjects. The authors declare that no experiments were performed on humans or animals for this study.

Confidentiality of data. The authors declare that they have followed the protocols of their work center on the publication of patient data.
Right to privacy and informed consent. The authors have obtained the written informed consent of the patients or subjects mentioned in the article. The corresponding author has this document.

\section{Conflicts of interest}

The authors declare no conflict of interest.

\section{Funding}

None.

\section{References}

1. Henderson LA, Cron RQ. Macrophage activation syndrome and secondary hemophagocytic lymphohistiocytosis in childhood inflammatory disorders: diagnosis and management. Paediatr Drugs. 2020;22:29-44.

2. Fukaya S, Yasuda S, Hashimoto T, Oku K, Kataoka H, Horita T, et al. Clinical features of haemophagocytic syndrome in patients with systemic autoimmune diseases: analysis of 30 cases. Rheumatology (Oxford). 2008;47:1686-91.

3. Jiang L, Tang K, Levin M, Irfan O, Morris SK, Wilson K, et al. COVID-19 and multisystem inflammatory syndrome in children and adolescents. Lancet Infect Dis. 2020;20:e276-88.

4. Del Aguila O, Domínguez-Rojas J, Garcés-Ghilardi R, Estupiñan-Vigil M, Alvarado-Gamarra G. Síndrome inflamatorio multisistémico pediátrico asociado a COVID-19: reporte preliminar de un hospital del Perú. Rev Peru Med Exp Salud Publica. 2021;38:180-2.

5. Aringer M, Costenbader K, Daikh D, Brinks R, Mosca M, Ramsey-Goldman R, et al. 2019 European League Against Rheumatism/American College of Rheumatology classification criteria for systemic lupus erythematosus. Arthritis Rheumatol. 2019;71:1400-12.

6. Gracia-Ramos AE, Saavedra-Salinas MÁ. Can the SARS-CoV-2 infection trigger systemic lupus erythematosus? A case-based review. Rheumatol Int. 2021;41:799-809.

7. Whittaker E, Bamford A, Kenny J, Kaforou M, Jones CE, Shah P, et al. Clinical characteristics of 58 children with a pediatric inflammatory multisystem syndrome temporally associated with SARS-CoV-2. JAMA. 2020;324:259-69.

8. Toubiana J, Poirault C, Corsia A, Bajolle F, Fourgeaud J, Angoulvant F, et al. Kawasaki-like multisystem inflammatory syndrome in children during the COVID-19 pandemic in Paris, France: prospective observational study. BMJ. 2020;369:m2094.

9. Borgia RE, Gerstein M, Levy DM, Silverman ED, Hiraki LT. Features, treatment, and outcomes of macrophage activation syndrome in childhood-onset systemic lupus erythematosus. Arthritis Rheumatol. 2018;70:616-24.

10. Bennett TD, Fluchel M, Hersh AO, Hayward KN, Hersh AL, Brogan TV, et al. Macrophage activation syndrome in children with systemic lupus erythematosus and children with juvenile idiopathic arthritis. Arthritis Rheum. 2012;64:4135-42.

11. Gupta D, Mohanty S, Thakral D, Bagga A, Wig N, Mitra DK. Unusual association of hemophagocytic lymphohistiocytosis in systemic lupus erythematosus: cases reported at tertiary care center. Am J Case Rep. 2016;17:739-44.

12. Thomas M, Robert A, Kuruvilla N, Uthamanand C. An unusual presentation of systemic lupus erythematosus as hemophagocytic lymphohistiocytosis in a male. Cureus. 2019;11:e5427.

13. Henter JI, Horne A, Aricó M, Egeler RM, Filipovich AH, Imashuku S, et al. HLH-2004: Diagnostic and therapeutic guidelines for hemophagocytic lymphohistiocytosis. Pediatr Blood Cancer. 2007;48:124-31. 